\title{
Impact of Family-Inclusive Case Management on Reentry Outcomes: Interim Report on the Safer Return Demonstration Evaluation
}

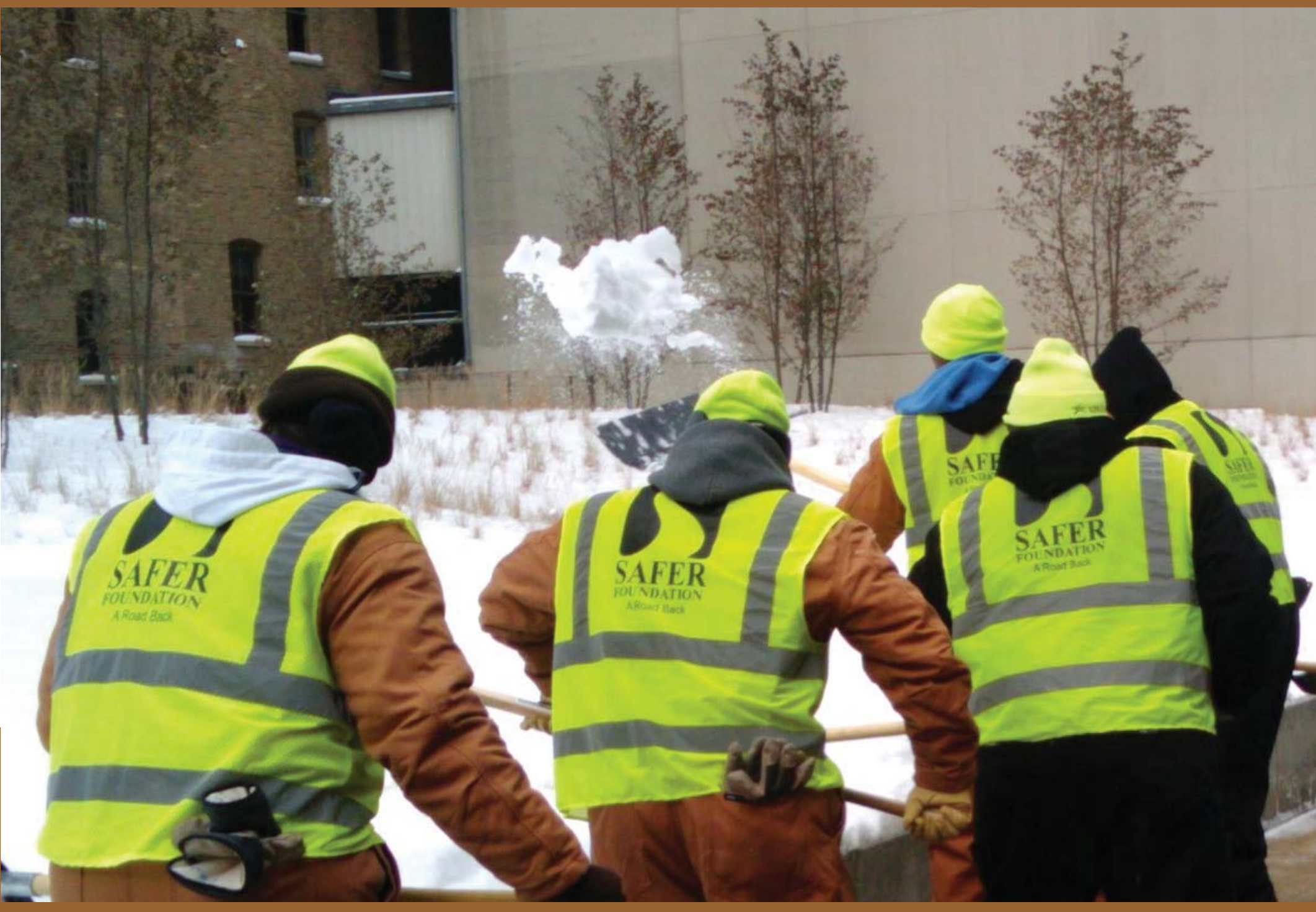

Jocelyn Fontaine

Douglas Gilchrist-Scott

Megan Denver

He Justice Policy Center | URBAN INSTITUTE 


\title{
Impact of Family-Inclusive Case Management on Reentry Outcomes: Interim Report on the Safer Return Demonstration Evaluation
}

\author{
Report Authors: \\ Jocelyn Fontaine \\ Douglas Gilchrist-Scott \\ Megan Denver \\ Principal Investigators: \\ Jocelyn Fontaine \\ Shelli Rossman
}

September 2011

2011. The Urban Institute. All rights reserved.

The views expressed are those of the authors and should not be attributed to the Urban Institute, its trustees, or its funders.

This project was supported by Grant \#06-DJ-BX-0681 and Grant \#DJ-BX-0034 awarded to the Illinois Criminal Justice Information Authority by the Bureau of Justice Assistance, Office of Justice Programs, U.S. Department of Justice. ${ }^{1}$ Points of view or opinions contained within this document are those of the authors and do not necessarily represent the official position or policies of the U.S. Department of Justice or the Illinois Criminal Justice Information Authority. Additional support for the evaluation of the Safer Return Demonstration is provided by the John D. and Catherine T. MacArthur Foundation.

The authors extend their gratitude to Darakshan Raja of the Urban Institute for her research assistance on the project, as well as Jesse Jannetta and Andrea Matthews of the Urban Institute and Ryan Shanahan and Margaret diZerega from the Vera Institute of Justice-Family Program, who provided support in their review of the final document. In addition, the authors would like to thank the Illinois Criminal Justice Information Authority, specifically Mark Myrent and Tracy Hahn, for their guidance and support throughout this project. Finally, the authors are beholden to the staff working on the Safer Return project-past and present-who have graciously offered their time to speak with the research team many times over the past several years.

\footnotetext{
${ }^{1}$ This deliverable was 100 percent funded by federal dollars through the Illinois Criminal Justice Information Authority. The total project was funded in the amount of $\$ 130,616$.
} 


\section{Table of Contents}

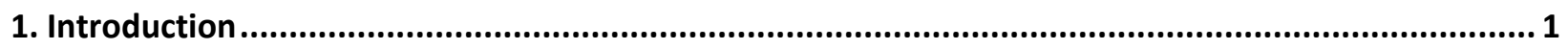

2. Brief Introduction to the Safer Return Demonstration ............................................................ 2

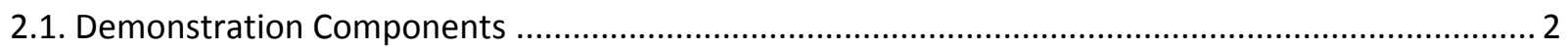

2.2. Role of Family-Inclusive Case Management ….............................................................................. 2

3. Evaluation of the Safer Return Demonstration .......................................................................... 4

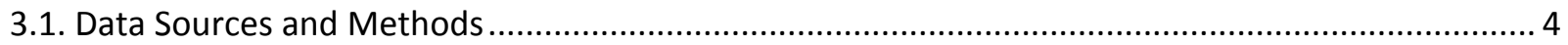

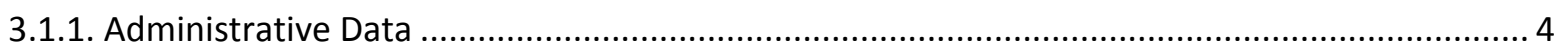

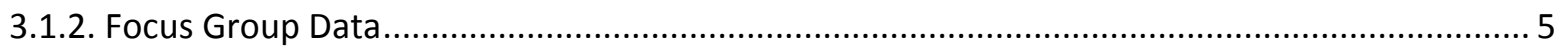

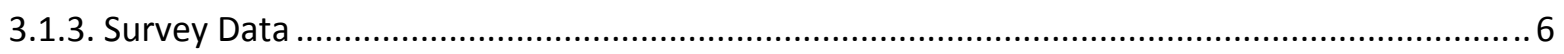

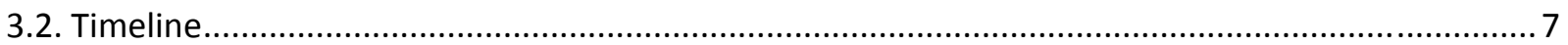

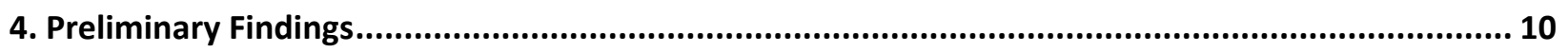

4.1. Logic of the Family-Inclusive Case Management Model ............................................................ 10

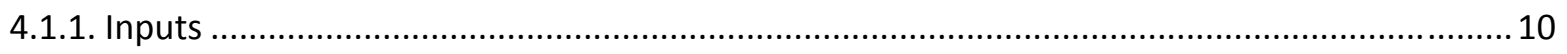

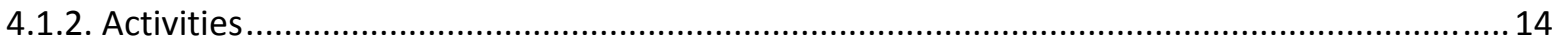

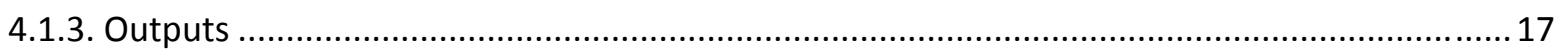

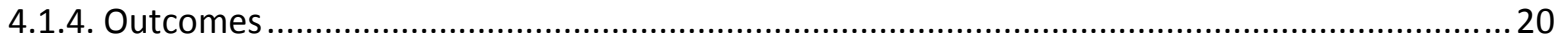

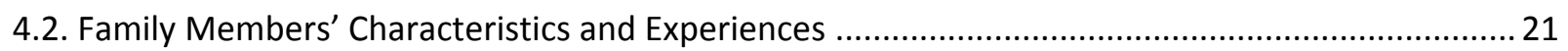

4.3. Reflections from Family Members and Formerly Incarcerated Persons ...................................... 25

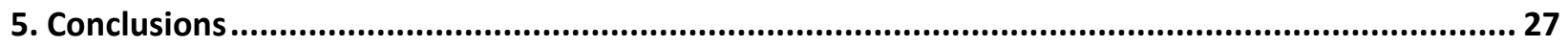

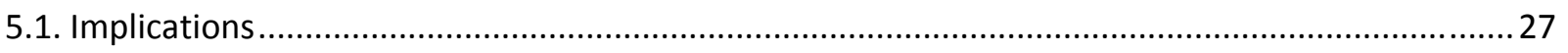

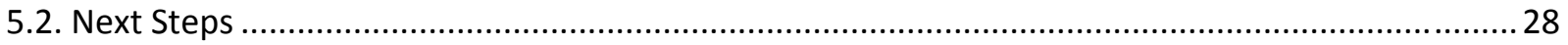

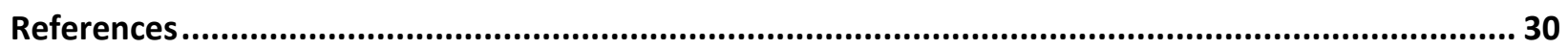




\section{Introduction}

As dozens of previous studies have demonstrated, individuals released from prison face a host of challenges as they return to their communities. Individuals experience difficulties finding gainful employment and stable housing, maintaining sobriety and abstinence from drugs, and avoiding risky people and places upon release from incarceration. Moreover, formerly incarcerated persons often have difficulty tapping into the services they need to address their substance and alcohol abuse, mental and physical health issues (Travis et al. 2001, Travis \& Visher 2005). The obstacles individuals face upon return to the community are problematic for both policymakers and practitioners because many of these issues - such as substance abuse, lack of employment, and lack of housing-are associated with a greater likelihood of recidivism (Solomon et al. 2006, Tripodi et al. 2010, Visher et al. 2004).

Previous research has shown that families are important sources of social support for individuals released from incarceration (La Vigne et al. 2004, Sullivan et al. 2002, Visher \& Courtney 2007, Visher et al. 2004), and individuals often rely on their families and broader social networks for more tangible support and resources, such as housing, income, and employment opportunities, immediately upon their release from incarceration (Visher \& Courtney 2007). Visher and colleagues (2004) found that intimate partner and family relationships and support were significantly related to positive employment and substance abuse outcomes for formerly incarcerated persons; Visher and Courtney (2007) found that 25 percent of sampled men returning to Cleveland, Ohio, cited their family members as the "most important thing keeping them out of prison." This is noteworthy since because the families and social networks of formerly incarcerated persons may offer a low-cost vehicle for leveraging institutional investments to reduce recidivism.

In recent years, family-inclusive reentry models have been implemented in order to utilize the resources and strengths of families and support networks of formerly incarcerated persons to improve reentry outcomes. The research on family-inclusive reentry models has been promising (see Bradley 1995, Quinn \& Van Dyke 2004, Selber et al. 1993, Visher et al. 2004). This interim report focuses on the familyinclusive case management component of the Safer Return Demonstration, a comprehensive, community-based prisoner reentry model, implemented in the Garfield Park neighborhood of Chicago, Illinois, with funding from the John D. and Catherine T. MacArthur Foundation. The Safer Return Demonstration uses a family-inclusive reentry model implemented by case managers called "reentry coaches," based on a model developed by Family Justice. ${ }^{2}$

The Urban Institute (UI) is conducting a process and outcome evaluation of the family-inclusive case management model of the Safer Return Demonstration, with federal funding through the Illinois Criminal Justice Information Authority. As part of the evaluation, UI has completed this interim report, which covers the first two years of the evaluation, July 2009 through June 2011 . The report begins by briefly outlining the Safer Return Demonstration and how the UI evaluation, which uses a quasiexperimental design, will examine the extent to which the demonstration is meeting its intended goals. The majority of the report is focused on describing the logic of the family-inclusive case management model, based on dozens of interviews and focus groups with stakeholders, case managers, reviews of administrative records and program materials, and focus groups with family members and formerly incarcerated persons. The report includes descriptions of the family members of the formerly incarcerated persons in the research sample, based on survey data. The report concludes with next steps for the evaluation and preliminary implications based on the research findings to date.

\footnotetext{
${ }^{2}$ The nonprofit organization Family Justice closed in late 2009. The organization's national training and technical assistance work continues as the Family Justice Program of the Vera Institute of Justice.
}

1) P a g e 


\section{Brief Introduction to the Safer Return Demonstration}

Designed jointly by the Urban Institute and the Safer Foundation, the Safer Return Demonstration is a multiyear, research-based project that intends to increase public safety and the successful reintegration of people returning from prison by sharing responsibility among formal and informal social networks using a three-pronged approach: 1 ) addressing key individual needs, including access to gainful employment opportunities and stable housing; 2 ) introducing system reforms, including comprehensive, family-inclusive case management and neighborhood-based parole officers; and 3) improving the local conditions that present barriers to success, including limited access to pro-social activities and positive role models. The demonstration is being implemented in one high-density prisoner reentry community in Chicago: Garfield Park. The demonstration is based on the idea that the whole community must be addressed and engaged to impact prisoner reentry positively.

The Safer Foundation is implementing the program with the goal of functioning as an intermediary. Specifically, the Safer Foundation's role as the justice intermediary for Safer Return is to: 1) lead efforts to institute comprehensive and coordinated responses to formerly incarcerated persons and their families; 2) organize communities to support formerly incarcerated persons and their families; 3 ) identify and coordinate policy levers; 4) facilitate and oversee local partnership formation; 5) provide training and technical assistance to build community and institutional capacity; 6) advocate policies and practices for reform; 7) serve as a fiscal administrator; and 8) lead efforts toward sustainability. The Urban Institute is evaluating the program through a rigorous process, impact, and economic evaluation focused on formerly incarcerated persons, their family and social support members, and the community.

\subsection{Demonstration Components}

Adults returning from the Illinois Department of Corrections (IDOC) to the Garfield Park community are eligible to participate in the Safer Return Demonstration, regardless of their gender, age, race, criminal charge, or history. The program is voluntary, and individual participants are offered a host of pre- and post-release services that include exit orientations in prison and mentoring, housing, job readiness training, and transitional employment in the community. The case management component of the demonstration is the core of the program and is based on a strengths-based, family-focused model developed by Family Justice. In addition to the empirical foundation underlying the case management component, each of the other components of the Safer Return model is also based on best and promising practices in prisoner reentry.

\subsection{Role of Family-Inclusive Case Management}

The case management component of the Safer Return project was developed based on Family Justice's Bodega Model ${ }^{\circledR}$. Through previous research, the Bodega Model has been found to reduce substance abuse and decrease the number of arrests and convictions among program participants compared to nonparticipants (Sullivan et al. 2002). More generally, family-focused case management techniques that include a broad definition of family have been shown to be effective ways to reduce the likelihood that an individual will return to criminal activity (Bradley 1995, Quinn \& Van Dyke 2004, Selber et al. 1993, Visher et al. 2004). In addition to being family focused, the Bodega Model is a strengths-based case management approach. Strengths-based approaches attempt to rebalance the emphasis from participant pathologies and deficits toward participant strengths. This approach builds on narratives of resilience, positive psychology, empowerment, and therapeutic approaches to capitalize on individuals' strengths and their motivation and desire for change to address daily problems of living (DeJong \& Berg 2002). The strengths-based approach focuses on assessing and leveraging participant capabilities, talents, and resources to support change and solve problems from a positive perspective, which has 
been effective with families, substance abusers, and persons with mental health issues (Early \& GlenMaye 2002). Belief in the participant's strength and ability to change has also been found to foster motivation rather than resistance to change (Clark 2005).

Using the strengths-based, family-focused approach, the Bodega Model is comprehensive. For the Safer Return Demonstration, the reentry coaches implement the Bodega Model through-

- Assessing the strengths, risks, and needs of formerly incarcerated persons through familyfocused, strengths-based tools, such as genograms, ${ }^{3}$ ecomaps, ${ }^{4}$ and the Relational Inquiry Tool, ${ }^{5}$ as well as validated risks and needs assessments, such as The Texas Christian University Criminal Justice Risk Assessment Tool; ${ }^{6}$

- Developing individualized reentry plans based on the strengths, risks, and needs assessments;

- Referring and linking individuals to services based on their reentry plans; and

- Monitoring participant progress.

Consistent with the Bodega Model, the reentry coaches use a broad definition of "family" to include not only blood relatives, but also close friends, mentors, and others who play a significant role in the formerly incarcerated persons' lives. In Safer Return, individuals are the focus of the case management services, though family members are encouraged to participate in the individuals' reentry process and are eligible to receive a limited amount of resources. This is a departure from the Family Justice model; the Bodega Model requires that at least one family member participate in case management. While the Safer Return Demonstration strives for family member participation, their participation in the case management component is not a requirement (discussed further below).

${ }^{3}$ The genogram is a diagram of a person's family and social network. This family mapping tool identifies the age, gender, and the nature of a person's relationships (positive, conflicted, or neutral). The participant and others identify which individuals to include in the diagram, often in response to questions asked by the case manager. A genogram may also include other information relevant to the family and social network, such as employment, education, mental health, and involvement in the justice system. See http://www.vera.org/centers/family-justice-program\#/content/tools-methods-family-justice-program.

${ }^{4}$ The ecomap is a diagram of the government and community resources the participant and his/her family use, including informal and formal organizations. Examples of informal organizations include the barber shop, corner deli, the community garden, and the local basketball league. Examples of formal organizations include government and private agencies such as a school, a community-based agency providing preventive services, a drug treatment program, or a peer support group at a local ministry. See http://www.vera.org/centers/familyjustice-program\#/content/tools-methods-family-justice-program.

${ }^{5}$ The Relational Inquiry Tool is a series of questions designed to prompt conversations with incarcerated men and women about the supportive people in their lives. See diZerega \& Agudelo 2011.

${ }^{6}$ http://www.ibr.tcu.edu/pubs/datacoll/datacoll.html 


\section{Evaluation of the Safer Return Demonstration}

As previously mentioned, $\mathrm{UI}$ is conducting a process, impact, and economic evaluation of the Safer Return Demonstration. The full evaluation of the Safer Return Demonstration is funded by the MacArthur Foundation and focuses on whether the entire suite of services is an effective means to improve outcomes for formerly incarcerated persons, specifically formerly incarcerated men, ${ }^{7}$ their family and social support members, and community members in the long term. Findings from the longterm evaluation are expected to be published in spring 2013. This interim report, with federal funding through the Illinois Criminal Justice Information Authority (ICJIA), is focused on the efficacy of the family-inclusive case management component exclusively and on the short-term outcomes attendant to this component. Specifically, the ICJIA evaluation includes a process and outcome evaluation of the family-inclusive case management services to determine whether this type of service delivery impacts individual- and family-level outcomes. Both the MacArthur- and ICIIA-funded evaluations use a quasiexperimental design, focused on individuals and family members in the Safer Return program compared to individuals and family members released to a comparison Chicago community. Based on Ul's assessment of administrative data on crime, incarcerated persons' release patterns, and sociodemographic characteristics, as well as interviews with key city stakeholders, the West Englewood neighborhood on Chicago's south side was chosen as the comparison community for the Safer Return evaluation.

Using multiple data sources, discussed in detail below, the process evaluation of the family-inclusive case management model documents the operations of the model, the barriers to and facilitators of successful operations, and whether critical program operations are achieved. The outcome evaluation of the family-inclusive case management model focuses on whether individuals in the Safer Return program and their family members exhibit better short-term outcomes than comparable formerly incarcerated persons and their family members who did not participate in the Safer Return program.

\subsection{Data Sources and Methods}

To document the progress and performance of the family-inclusive case management model and how it is related to expected outcomes, the evaluation uses both qualitative and quantitative data sources, including: 1) administrative data, such as programmatic information and official government records; 2 ) focus groups with individuals, family members ${ }^{8}$ of individuals released to the treatment and comparison communities, and reentry coaches; and 3 ) survey data of individuals and family members.

\subsubsection{Administrative Data}

The Urban Institute has conducted more than one dozen site visits to Chicago since Safer Return's implementation to-

1. Conduct semi-structured interviews with program stakeholders, including each of the case managers and their supervisors;

2. Observe training sessions for case managers and other program staff, such as the neighborhoodbased parole officers, conducted by Family Justice on the Bodega Model;

\footnotetext{
${ }^{7}$ Due to limited resources and relatively lower rates of women as compared to men returning to the Garfield Park community from prison, only adult men and their family/social support members (of any gender) are included in the UI evaluation.

${ }^{8}$ Hereafter, "family member" is intended to be synonymous with "family and social support member," consistent with Safer Return's broad definition of family.
} 
3. Observe case staffings for participants and other components of the Safer Return program that participants are offered (e.g., exit orientations, mentoring);

4. Conduct document reviews of case management tools, such as the case managers' standard operating procedures manual; and

5. Conduct reviews of the case management database, called Axiom.

Qualitative, contextual information has been gathered through these observations and interviews on program practices, procedures, and processes. Observations have provided objective measures of how the program has operated, as rated by the UI evaluation team, rather than relying on the reports and opinions of stakeholders involved in program implementation. Through these data, UI has documented the development, challenges, and changes in program operations over time, mostly to support the process evaluation. These data collection activities are used to detail the program context, program operations, processes, and the links between program inputs, performance and activities (outputs), and outcomes, as well as to make recommendations on potential program modifications, expansions, and sustainability opportunities.

In addition to the administrative and programmatic information listed above, UI has accessed official government and programmatic records to determine various outcomes associated with the Safer Return program and the family-inclusive case management, to support the outcome evaluation. These include the following:

1. Administrative data on formerly incarcerated persons in the treatment and comparison communities; and

2. Program records on individual participants' and family members' service needs and receipt of services, based on the Safer Return Axiom database.

Administrative data on outcomes attendant to the Safer Return program and the family-inclusive case management include criminal justice records from the Illinois Department of Corrections and the Chicago Police Department on arrests, parole violations, and reincarceration, and employment insurance records from the Illinois Department of Employment Services.

\subsubsection{Focus Group Data}

To glean a qualitative perspective on the program operations and processes, $U$ I researchers have conducted separate focus groups with formerly incarcerated persons in the Safer Return program, formerly incarcerated individuals in the comparison community, family members of Safer Return participants, and family members of comparison group participants. Focus groups were held for each subgroup in January 2010, June 2010, and November 2010. Individuals and family members were recruited directly by UI staff through mailings and telephone calls, using the administrative and programmatic data previously described. UI staff facilitated each of the focus groups, and participants were provided a light dinner during the group discussion and compensated for their participation. Individuals and family members were asked to participate in the focus groups, which were each held in the community, and covered the following domains:

Formerly Incarcerated Persons-treatment and comparison

- Knowledge and preparation for the reentry process

- Contact and experiences with Safer Return program staff, other caseworkers, and service providers to facilitate the reentry process and reintegration in the community

- Role of family members and social support members in the reentry process 
- Sources of significant social support and contact during incarceration and after release

- Experiences and contact with children/dependents during incarceration and after release

Family/Social Support Members-treatment and comparison

- Knowledge and preparation of their family members' return to the community

- Contact and experiences with Safer Return program staff, other caseworkers, and service providers to facilitate the reentry process and reintegration in the community

- Relationship with returning family member during incarceration and after release

- Experiences and contact with children/dependents during incarceration and after release

- Personal needs for support from Safer Return program staff, other caseworkers, and service providers related to reentry process

These results provide qualitative, in-depth reflections on how the family-inclusive case management and other service provision has or has not affected changes in the reentry experience of individuals and their families. The focus groups helped researchers explore how formerly incarcerated members and family members benefited from the family-inclusive case management component and what and how additional services would be useful. In addition, the focus group data helped to thread themes through the findings of the quantitative data collection (discussed below) to help demonstrate: 1 ) what efforts are consistent with evidence-based (or promising) research models and appear to be working well; 2) what aspects of the program or family-inclusive case management can be strengthened by focusing on greater implementation fidelity or other mitigation activities; and 3) recommendations for strengthening the demonstration itself.

The administrative data and information gleaned from the focus groups help UI answer the following research questions on the performance and progress of the Safer Return family-inclusive case management model.

Process Evaluation: Does the Safer Return family-inclusive case management model....

Increase Safer Return participants' and their families/social supports' access to needed services?

Increase Safer Return participants' families/social supports' access to criminal justice organizations, serviceprovider agencies, and community- and faith-based agencies?

\subsubsection{Survey Data}

To gain a greater perspective on the importance of family-focused case management services on family outcomes, UI has surveyed a cohort of family members of the Safer Return program participants and family members of formerly incarcerated persons in the comparison community, beginning in spring $2010 .{ }^{9}$ Surveys of family members have been conducted in two waves, baseline and follow-up. Baseline surveys have been conducted in person four months after the formerly incarcerated person's release to the community and follow-up has been conducted by telephone, by mail, and in person six months following the baseline interview or ten months following the formerly incarcerated person's release. Family members are recruited into the study through formerly incarcerated persons in both communities. Formerly incarcerated males recruited into the study, in the Safer Return program and West Englewood, are asked to identify up to four adults who have been a significant source of emotional or material support, including biological family members, friends, mentors, pastors, or any other adult the formerly incarcerated person has deemed appropriate.

\footnotetext{
${ }^{9}$ Surveys of formerly incarcerated persons, in the Safer Return Program and the comparison community, are conducted with funding from the MacArthur Foundation.
}

6|P a g e 
The baseline and follow-up data collection tools were each designed to take approximately 20-30 minutes to complete. In addition to sociodemographic and behavioral characteristics of the family member, the baseline tool covers the following domains:

- Relationship to the formerly incarcerated person

- Experiences and types of contact with the formerly incarcerated person, pre-, during, and postincarceration

- Children/co-dependents with the formerly incarcerated person

- Experiences and types of contact children/co-dependents had with the formerly incarcerated person, pre-, during, and post-incarceration

- Provision of post-release resources for the formerly incarcerated person

- Experiences with social service agencies

- Challenges due to the formerly incarcerated person's return from prison

The follow-up survey was designed to explore the extent to which there were changes in the aforementioned domains since the baseline survey. Individuals are compensated for their participation in each survey wave, with a bonus for participating in both survey waves and for keeping their contact information current during survey waves.

\section{Outcome Evaluation: Does the family-inclusive case management model...}

Improve reentry outcomes for individuals (housing stability, increase employment stability, reduce substance abuse or recidivism)?

Increase the number of family members from whom the participant receives social support?

Strengthen informal support networks? In what ways?

Improve relationships between formerly incarcerated persons and their families?

Allow family/social support members to play a more active role in the reentry of formerly incarcerated persons returning to the community?

Open access to needed resources for family/social support members to better support the return of formerly incarcerated family members?

Help individuals spend an increased amount of time with or provide additional emotional support for family, particularly children?

Improve the economic stability of families/households of formerly incarcerated individuals?

Increase access of family members to parole or community-based service providers to garner support for their recently released family member?

Increase formerly incarcerated individuals' time spent in pro-social activities (e.g., attending religious services, going to parent-teacher activities, enrollment in recreational or educational pursuits)?

Increase child support payments by those with children?

Improve relationships between formerly incarcerated individuals and custodial parents?

\subsection{Timeline}

The original timeline for the study was 12 months, given the original contractual agreement between UI and ICIIA. To ensure that the study could be completed within 12 months, UI originally projected that enrollment into the surveys would proceed for approximately three months, leaving sufficient time for a six-month follow-up period, and time to collect, analyze, and report on survey, focus group, and administrative data. Focus groups were to be conducted at two points in time to coincide with the timing of the baseline and follow-up survey data collection. Using historical administrative data, UI expected that approximately 30 individuals would be released from prison and return to West Englewood and 30 formerly incarcerated persons would be enrolled in Safer Return, monthly. To achieve a sample size of family members of sufficient statistical validity, UI planned to survey up to two 
family members for each individual returning to the target communities, yielding a potential sample of 360 family members (180 associated with treatment subjects and an equivalent set for the comparison group). Baseline surveys with family members were intended to be conducted within one month of the formerly incarcerated person's release, with follow-up surveys conducted six months following the baseline survey.

Though funding for the evaluation became available in late June 2009, the project has been delayed for several reasons. Though administrative data collection and focus group sampling began close to project start-up, the survey component has been delayed significantly. Most important, there were significant delays in actual survey recruitment, owing to delays in receiving release data from the Illinois Department of Corrections (IDOC). Release data from IDOC are critical for study recruitment, as they provide access to the names and contact information of individuals eligible for the research study and, by extension, their family members. Researchers did not gain access to IDOC data until spring 2010, nearly one year following the study's start date. Also, once enrollment into the study began, two additional circumstances hampered enrollment even further.

First, fewer individuals have enrolled in Safer Return than expected. Second, researchers have had difficulty locating the identified sample, particularly in the treatment community. Due to the transient nature of the population under study, it has been difficult to locate and survey formerly incarcerated persons in the community. Difficulty locating formerly incarcerated persons has an impact on researchers' ability to locate family members. Third, the Safer Return program enrollment strategy changed over time. While Safer Return was originally designed to enroll participants pre-release-the case when evaluation funding became available from ICJIA-over time, Safer Return has enrolled a significant number of participants in the community. The average time between release from prison and program enrollment has been approximately 22 days.

As a result of these enrollment challenges, particularly the transient nature of the population under study and to accommodate community enrollment, UI decided to provide a longer window from prison release to sample recruitment. Presently, $\mathrm{UI}$ is recruiting family members into the study up to four months post-release of their formerly incarcerated family member. The follow-up period did not change and is defined as six months following the baseline survey. In addition, UI researchers have been using various mechanisms to increase sample enrollment, including: creating posters and flyers that identify the study opportunity, incentives, and researchers' contact information; working with IDOC and various program partners to display posters and flyers in prominent locations likely to be seen by the target population and/or their social support networks; making in-person visits to locations where potential sample members congregate to conduct the initial baseline screeners and baseline surveys; and mailing surveys to individuals with instructions on how to complete the surveys.

As shown in Table 1, the first year of recruitment into the survey sample was slower than expected. After three months, April 2010 through June 2010, family recruitment was fewer than 30. By March 2011,125 family members had been surveyed at baseline. To get closer to a number that will permit a more rigorous test of program effects, the goal is to survey approximately 300 family members. Given the current pace of recruitment, recruitment would need to continue for another year. While efforts to increase enrollment are continuing, the next step in the evaluation is to explore other analytic options assuming a smaller-than-desirable sample size. Presently, the study is expected to be complete by March 2012. 
Table 1: Snapshot of Survey Recruitment

\begin{tabular}{l|l|l|l|l|l|l|l|l|l|l|l|l}
\hline Year 1 (2010-2011) & $\begin{array}{l}\text { Apr } \\
\mathbf{1 0}\end{array}$ & $\begin{array}{l}\text { May } \\
\mathbf{1 0}\end{array}$ & $\begin{array}{l}\text { Jun } \\
\mathbf{1 0}\end{array}$ & $\begin{array}{l}\text { Jul } \\
\mathbf{1 0}\end{array}$ & $\begin{array}{l}\text { Aug } \\
\mathbf{1 0}\end{array}$ & $\begin{array}{l}\text { Sep } \\
\mathbf{1 0}\end{array}$ & $\begin{array}{l}\text { Oct } \\
\mathbf{1 0}\end{array}$ & $\begin{array}{l}\text { Nov } \\
\mathbf{1 0}\end{array}$ & $\begin{array}{l}\text { Dec } \\
\mathbf{1 0}\end{array}$ & $\begin{array}{l}\text { Jan } \\
\mathbf{1 0}\end{array}$ & $\begin{array}{l}\text { Feb } \\
\mathbf{1 1}\end{array}$ & $\begin{array}{l}\text { Mar } \\
\mathbf{1 1}\end{array}$ \\
\hline West Englewood Releases/month & 36 & $\mathbf{2 8}$ & $\mathbf{2 7}$ & $\mathbf{2 6}$ & $\mathbf{2 5}$ & 32 & 31 & 34 & 46 & 25 & 37 & 33 \\
\hline Baseline Surveys of FIPS (cum) & 8 & 8 & 13 & 34 & 48 & 56 & 65 & 65 & 71 & 74 & 80 & 88 \\
\hline Baseline Surveys of FAM (cum) & 7 & 8 & 8 & 23 & 36 & 42 & 49 & 49 & 58 & 61 & 66 & 73 \\
\hline Safer Return Enrollments/month & 19 & 23 & 14 & 34 & 31 & 22 & 20 & 14 & 29 & 26 & 11 & 42 \\
\hline Baseline Surveys of FIP (cum) & 0 & 0 & 8 & 8 & 14 & 16 & 21 & 25 & 46 & 51 & 53 & 62 \\
\hline Baseline Surveys of FAM (cum) & 0 & 0 & 7 & 7 & 10 & 16 & 21 & 21 & 36 & 41 & 43 & 52 \\
\hline
\end{tabular}

*FIPS=formerly incarcerated persons; FAM=family members 


\section{Preliminary Findings}

The following section describes the logic of the family-inclusive case management model, as well as the characteristics of the first 100 family members enrolled in the research study. The logic model is based on program information, focus groups with Safer Return participants and their family members, and interviews with the reentry coaches and other Safer Return stakeholders. The description of the first 100 family members includes summary statistics gleaned from the baseline surveys. The baseline descriptive statistics are summarized by community. As shown in Table 1, above, there are presently far more respondents in the West Englewood community (comparison) than the Garfield Park community (treatment). While new data collection methods are currently being implemented for the follow-up surveys (including mailed surveys and in-person survey invitations), the sample size is not yet large enough for meaningful description or analysis. Instead, themes from family focus group sessions are discussed relative to the baseline survey responses.

\subsection{Logic of the Family-Inclusive Case Management Model}

The role of the family-inclusive case management model within the Safer Return Project is substantial. It is the hub of participant services, which include initial program enrollment through Welcome Home Panels; initial and periodic assessments of strengths, risks, and needs; referrals to both internal and external services; and coordination with neighborhood-based parole officers.

The Safer Return family-inclusive case management logic model is summarized in Figure 1. The logic model was developed through semi-structured interviews with reentry coaches and administrative staff, more than a dozen observations of program trainings and operations, and reviews of program materials. The model displayed in Figure 1 is not inclusive of the full Safer Return program. Rather, it describes the theoretical framework of the case management component, highlighting interactions with other program components. The model is split into four main elements: 1) inputs; 2) activities; 3) outputs; and 4) outcomes.

\subsubsection{Inputs}

As shown in Figure 1, program inputs are split into three categories: staff, partnerships, and resources.

\section{Staff}

Reentry coaches are the primary staff members involved in the family-inclusive case management. They are responsible for day-to-day interactions with participants, and perform the bulk of the program activities such as program intake, assessments, counseling/life coaching, referrals to service providers, and coordination with parole (described in more detail below). Each of the reentry coaches is a full-time employee who dedicates 100 percent of his or her time to case management activities for the Safer Return project. All of the reentry coaches have prior case management experience; some have a criminal history; and several have degrees in counseling and criminal justice. Each reentry coach has a target caseload of 30 individuals, though actual caseloads have varied during the life of the program. The number of reentry coaches also has varied over time, from a high of ten coaches to a low of four, depending on the number of active program participants in the community.

The Lead Reentry Coach, a full-time position in the Safer Return case management team, provides dayto-day supervision of the reentry coaches. The position is intended to assign participants to case managers, provide guidance with participant issues, perform general office management, and serve as the liaison between the reentry coaches and the administrative staff.

As displayed in Figure 2, administrative oversight is performed by two organizations: Treatment Alternatives for Safe Communities (TASC) and the Safer Foundation. TASC is a subcontractor to the Safer 
Figure 1. Safer Return Case Management Logic Model

\section{Inputs}

Staff:

- Reentry Coaches

- Lead Reentry Coach

- Program Administrator (TASC)

- Reentry Coach Manager (Safer)

\section{Safer Return Program}

Partners:

- Treatment Alternatives for Safe Communities (TASC)

- People's Church of the Harvest

- National Association for the Empowerment of Formerly Incarcerated Offenders

\section{Local Organizations:}

- Safer Foundation

- Illinois Department of

Corrections (IDOC)

- Non-Safer Return

Service Providers

- Community- and FaithBased Organizations

Resources:

- Ongoing Training

- Standard Operating

Procedure Manual

- Participant Assistance

Funds

- Community Field Office

- Axiom Database

\section{Participant and Family-Centered}

\section{Activities}

- Welcome Home Panels/Exit

Orientations

- Intake assessments

- Reentry planning

- Preliminary introduction to family members

- Communication with participants

- Communication with family and other social support members

- Direct provision of services and service referrals to other providers

- Monitoring service provision and client progress

- Advocacy

\section{Resource Building and Maintenance}

\section{Activities}

- Recruiting program partners

- Coordinating with service providers and community partners

- Soliciting donations

Parole Co-case Management Activities

- Co-case management meetings

- Information sharing

- Sponsored movement to participate in program activities
Internal Outputs

\section{Reentry Coach Outputs}

- Transportation services

- Material goods

- Life coaching/counseling

- Crisis intervention

- Job application and resume assistance

- Substance abuse assessments

Other Safer Return Program Outputs

- Job readiness training

- Sector managers

- Civic community works (CCW)

- Government work crews

- Group housing

\section{External Outputs}

Non-Safer Resource Referrals

- Mental health and substance abuse treatment, education and job training programs, anger management,

transitional housing

\section{Financial Assistance to Individual}

- Education funds

- Emergency funds

Pro-social Activities and Supports

- Linkage with faith-based and other community partners

\section{Short Term Outcomes (1 year)}

- Participate in Safer Return Programs

- Complete Job Readiness Training

- Find Employment

- Enroll in an education/job training program

- Secure transitional housing

- Secure permanent housing

- Secure mental health treatment

- Secure physical health treatment

- Secure substance abuse treatment

- Complete anger management classes

- Attend pro-social community activities

- Reunification with family and children

\begin{tabular}{|l|}
\hline - Long Term Outcomes (>1 year) \\
- Permanent employment \\
- Reduced recidivism \\
- Inproved family relationships \\
- Increased communical and mental health \\
and pro-social activity
\end{tabular}


Foundation for the Safer Return project, hired to implement the family-inclusive case management model. TASC specializes in clinical case management of mentally ill and substance-abusing populations in the Illinois criminal justice, corrections, juvenile justice, child welfare, and other public systems. The reentry coaches and lead reentry coach for Safer Return have been hired by TASC directly. As part of the TASC administrative staff, the Program Administrator oversees multiple TASC contracts. For Safer Return, the position is intended to provide administrative oversight of the lead reentry coach, monitoring the overall performance of the reentry coaches and coordinating with Safer Foundation to meet TASC's contractual obligations.

In addition to TASC's administrative oversight, the Safer Return executive staff program includes a fulltime Reentry Coach Manager, ${ }^{10}$ who directly supervises the lead reentry coach and reentry coaches and coordinates their efforts with the other components in the Safer Return Demonstration Project. This helps to ensure that participants are served effectively and have seamless access to the other Safer Return components. The Reentry Coach Manager is also responsible for coordinating the Welcome Home Panels (discussed in more detail below).

Figure 2: Safer Return Case Management Organizational Chart

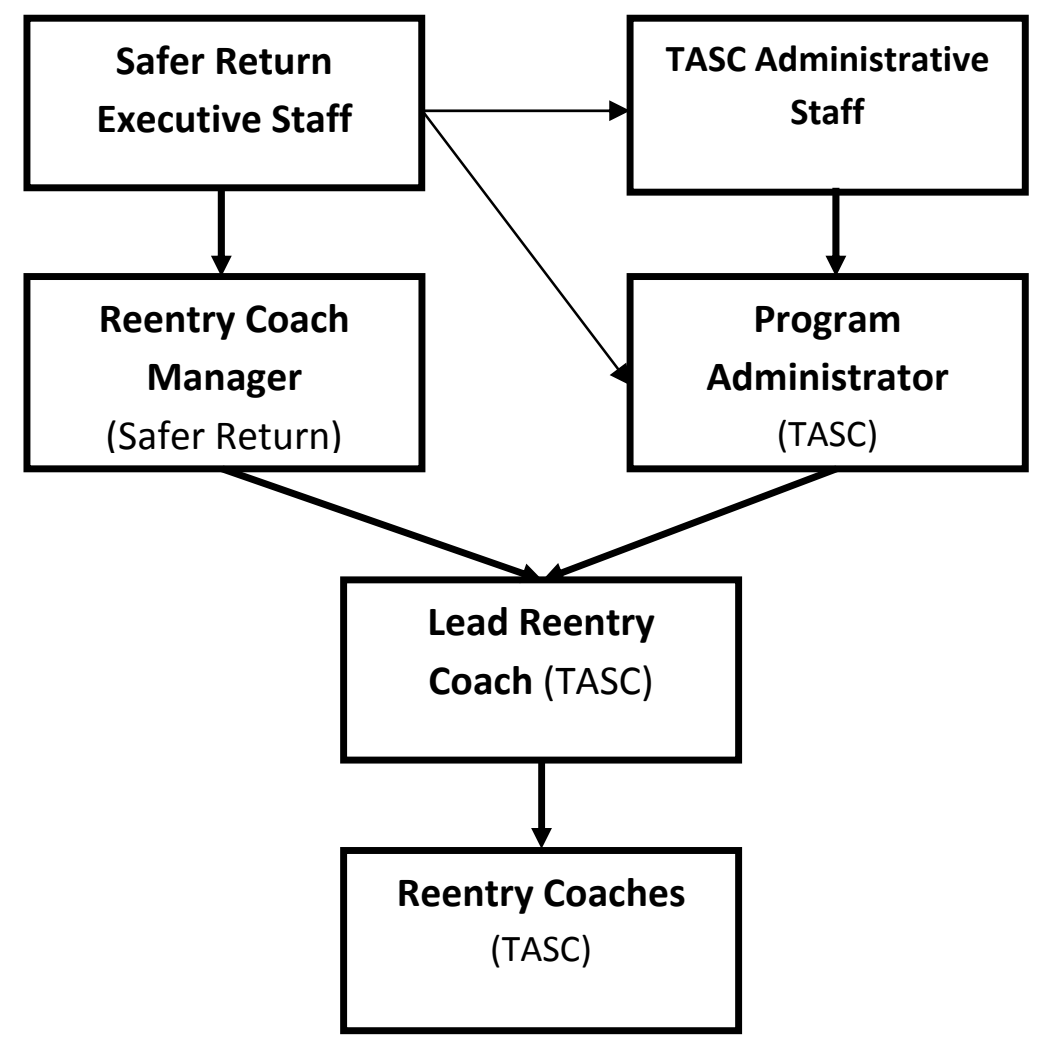

${ }^{10}$ The Reentry Coach Manager position was eliminated from the program 2.5 years after the program began. 


\section{Contracted Partners}

Safer Return has contracted with a variety of partners to administer various program components. Organizations were selected through a competitive bidding process, with strong emphasis placed on preexisting knowledge of and capacity with serving the reentry population in the Garfield Park community. The roles of these organizations are detailed in Table 2.

Table 2: Safer Return Program Partners

\begin{tabular}{|c|c|}
\hline $\begin{array}{l}\text { Treatment } \\
\text { Alternatives for Safe } \\
\text { Communities, Inc. } \\
\text { (TASC) }\end{array}$ & $\begin{array}{l}\text { TASC is contracted to administer the family-inclusive case management component of } \\
\text { Safer Return. In addition, TASC supports the program by leveraging its existing service } \\
\text { provider relationships to enhance participant services. }\end{array}$ \\
\hline $\begin{array}{l}\text { People's Church of } \\
\text { the Harvest }\end{array}$ & $\begin{array}{l}\text { People's Church of the Harvest, a local Christian church serving the community since 1943, } \\
\text { has been contracted to organize pro-social activities within the Garfield Park community, } \\
\text { such as family movie nights, basketball tournaments, and computer skills training, and to } \\
\text { organize community participants in the Welcome Home Panels. }\end{array}$ \\
\hline $\begin{array}{l}\text { National Association } \\
\text { for the } \\
\text { Empowerment of } \\
\text { Formerly } \\
\text { Incarcerated } \\
\text { Offenders (NAEFIO) }\end{array}$ & $\begin{array}{l}\text { NAEFIO organizes the mentoring component of Safer Return (see Outputs below). In } \\
\text { addition to its work for Safer Return, NAEFIO organizes other mentoring programs across } \\
\text { Chicago for formerly incarcerated persons. The founder of NAEFIO conducts extensive } \\
\text { outreach to gang-involved youth in Illinois and is frequently invited to speak to local, state, } \\
\text { and national leaders on the issues of successful reentry and gang reduction. }\end{array}$ \\
\hline
\end{tabular}

In addition to the above contracted partners, Safer Return leverages existing Chicago and Garfield Park resources to meet its participants' needs. Multiple external organizations that serve Safer Return participants are described in Table 3.

Table 3: Local Organizations

\begin{tabular}{l|l}
\hline Safer Foundation & $\begin{array}{l}\text { The Safer Return program is one of multiple programs administered by the Safer } \\
\text { Foundation in Illinois and lowa to aid individuals with criminal records. In particular, the } \\
\text { Safer Foundation provides job readiness training courses for the Safer Return participants. } \\
\text { The Safer Return project does not fund or oversee the other Safer Foundation programs, } \\
\text { but will refer participants to these programs. }\end{array}$ \\
\hline $\begin{array}{l}\text { Illinois Department } \\
\text { of Corrections (IDOC) }\end{array}$ & $\begin{array}{l}\text { IDOC supports the family-inclusive case management in two critical ways: 1) by assigning } \\
\text { dedicated, community-based parole officers who serve Safer Return participants and work } \\
\text { closely with the reentry coaches to coordinate efforts (see co-case management activities, } \\
\text { below); and 2) by facilitating the reentry coaches' pre-release program enrollment (see } \\
\text { Welcome Home Panels, below) through in-person visits and teleconferences at IDOC state } \\
\text { prison facilities and Adult Transitional Centers (ATC). }\end{array}$ \\
\hline $\begin{array}{l}\text { Non-Safer Return } \\
\text { Service Providers }\end{array}$ & $\begin{array}{l}\text { Safer Return has relationships with several housing, substance abuse, and mental health } \\
\text { treatment providers. While each relationship varies, in general, these partnerships reduce } \\
\text { the referral and waiting time for participants in need of services. Additionally, the } \\
\text { program has partnerships with vocational and academic organizations to expedite } \\
\text { acceptance into a variety of educational and training programs for Safer Return } \\
\text { participants. }\end{array}$ \\
\hline $\begin{array}{l}\text { Community- and } \\
\text { Faith-Based } \\
\text { Organizations }\end{array}$ & $\begin{array}{l}\text { Safer Return executive staff members attend community advisory board meetings to } \\
\text { recruit community- and faith-based organizations. In turn, these organizations work to } \\
\text { provide pro-social activities and resources within the Garfield Park community, in addition } \\
\text { to those organized by the People's Church of the Harvest. }\end{array}$ \\
\hline
\end{tabular}




\section{Resources}

The Safer Return Program includes a variety of resources, listed in Table 4, to assist staff in carrying out the family-inclusive case management component.

\section{Table 4: Safer Return Program Resources}

\begin{tabular}{l|l}
\hline Ongoing Training & $\begin{array}{l}\text { The reentry coaches and parole officers were initially trained on the Bodega Model by } \\
\text { Family Justice. The Safer Return program manager and lead reentry coach provide } \\
\text { periodic training sessions for reentry coaches and parole officers to reinforce the basic } \\
\text { tenets of the family-inclusive case management model. }\end{array}$ \\
\hline $\begin{array}{l}\text { Standard Operating } \\
\text { Procedures (SOP) }\end{array}$ & $\begin{array}{l}\text { The SOP, developed by the Safer Return executive staff, Family Justice, and TASC } \\
\text { leadership, serves as a resource for reentry coaches. The SOP outlines the expectations for } \\
\text { reentry coaches, the principles and tools of family case management, procedures for } \\
\text { referring participants to services, and how to track participant outcomes in the Axiom } \\
\text { Database. }\end{array}$ \\
\hline Participant & $\begin{array}{l}\text { There are modest financial resources, administered by the Safer Return executive staff } \\
\text { that the reentry coaches can distribute to program participants to meet pressing } \\
\text { individual needs (see Outputs, below). }\end{array}$ \\
\hline Community Field \\
Office & $\begin{array}{l}\text { The reentry coaches and lead reentry coach work from a community-based office in } \\
\text { Garfield Park, which is separate from other Safer Return programs and the executive staff. } \\
\text { The office serves as the home base for the reentry coaches, hosts community Welcome } \\
\text { Home Panels (see Activities, below), and is an alternative location for the community- } \\
\text { based parole officers to work while in the field. This community site helps facilitate } \\
\text { communication among the reentry coaches, the parole officers, and participants; } \\
\text { demonstrates the IDOC and Safer Return collaboration to participants; and further } \\
\text { solidifies the program's connection to the Garfield Park community as a whole. }\end{array}$ \\
\hline Axiom Database & $\begin{array}{l}\text { Safer Return employs a computer-based participant management database called Axiom. } \\
\text { Axiom is designed to hold all participant records, including a comprehensive record of } \\
\text { participant-program interactions. All Safer Return staff and reentry coaches have access to } \\
\text { and input data into Axiom. }\end{array}$ \\
\hline
\end{tabular}

\subsubsection{Activities}

To implement the family-inclusive case management components, the staff members perform a variety of activities, from working directly with participants in their reentry process to building and maintaining the partnerships with service providers and government agencies that can assist participants in negotiating the reentry process. In the logic model (Figure 1), these activities are sorted into three categories according to their target audience.

\section{Participant and Family-Centered Activities}

Since the family-inclusive case management model is intended to recognize the critical role that family members play in the reentry process, the reentry coach position is designed to support and strengthen the entire family unit through its case management services. As such, the activities involved in the case management component are diverse and intended to engage both the individual participants and their family and social support members, where possible. Activities centered on participants and their family and other social support members are listed in Table 5.

Table 5: Participant and Family-Centered Activities

\begin{tabular}{l|l}
\hline Welcome Home & Participants are enrolled in the Safer Return Project through Welcome Home Panels \\
\hline
\end{tabular}




\section{Panels/Exit Orientations}

(WHPs). WHPs take place in IDOC facilities or via videoconference. WHPs also occur periodically in the community, intended for those who are within 45 days of their release and who did not participate in a facility or videoconference WHP. During the WHP, reentry coaches, along with the project's assigned parole officers and local community members, welcome the potential participant back to the Garfield Park neighborhood, pledge their support for the potential participant, and introduce the Safer Return project. The WHPs are the vehicle by which pre-release planning for those returning to the Garfield Park community areas begins.
Intake Assessments
After enrollment, reentry coaches perform a variety of risk and needs assessments. Information collected in these assessments includes information about family and social support members - to understand the family dynamic better and identify appropriate family members to include in the case management activities; educational, criminal, medical treatment, and substance abuse treatment histories; parole board orders; housing and other contact information; goals for the reentry process; and assessments pre- and post-release, depending on time of enrollment and IDOC facility location. Information collected at intake is stored in Axiom.

Based on the intake assessments and introductions, the reentry coaches work with participants to create reentry plans. This plan outlines the participant's goals, as well as a timeline in which the participant wishes to meet them. The plan identifies specific resources and program partners that are available to help the participant succeed. The reentry plan provides a framework for the case management, listing specific responsibilities of the reentry coach, the individual, and the family member (where appropriate). It also provides a metric against which the individual's progress can be measured. For individuals enrolled in Safer Return as inmates, reentry coaches return to the prison to do preliminary reentry planning at least 30 days before release. Pre-release reentry plans are then updated and expanded as necessary once the participant returns to the community. For participants who are enrolled post-release or cannot complete prerelease meeting $s$ with reentry coaches, the reentry planning process takes place in the community after release. The participant's reentry plan is stored in Axiom.

\begin{tabular}{l} 
Preliminary \\
Introduction to \\
Family Members \\
\hline Communication with \\
Participants
\end{tabular}

With the permission of the participant, reentry coaches contact the family and social support members to introduce themselves and the project, and to begin engaging the family and social support members in the case management activities.

Reentry coaches meet with individual participants regularly to track their progress and address any outstanding issues. Most meetings occur in the Safer Return office, which is based in the Garfield Park community. Some contact occurs by telephone or visits to the participant's home. While none of the reentry coaches is on call outside normal work hours, reentry coaches do often work outside of the required standard office hours of 9 a.m. -5 p.m. Monday through Friday. The frequency of these meetings varies depending on the engagement of the participant and the time since release. There is no formal scheme with which participants are seen; in general, those who are higher risk, have immediate critical needs, or have recently returned are seen more often than those who have lower risk and needs or have been in the community longer.

Reentry coaches seek to keep family and other social support members aware of and engaged in the participants' reentry processes. Family and other social support members can assist the reentry coach by helping them locate a Safer Return participant who is transient or residentially instable, by encouraging the participant to engage in the program, and by providing resources to help meet the participant's needs. In addition to communicating the participants' progress, reentry coaches provide limited services to participants' family and social support members directly (see Outputs, below). 


\begin{tabular}{l|l}
\hline $\begin{array}{l}\text { Direct Provision of } \\
\text { Services and Service } \\
\text { Referrals to Other } \\
\text { Providers }\end{array}$ & $\begin{array}{l}\text { The reentry coaches serve as the gate keepers, determining which services each } \\
\text { participant may receive based on their reentry plan and eligibility for services. Clients } \\
\text { receive services directly from the reentry coaches as well as referrals to other service } \\
\text { providers within and outside of the Safer Return program (see Outputs, below). }\end{array}$ \\
\hline $\begin{array}{l}\text { Monitoring Service } \\
\text { Provision and Client }\end{array}$ & $\begin{array}{l}\text { The Safer Return program tracks participants' progress electronically through the Axiom } \\
\text { database. Every interaction with a reentry coach, service referral, and co-case } \\
\text { management session is logged in the system, along with their outcomes. If the participant } \\
\text { is referred to a Safer Return or Safer Foundation program, the program staff members } \\
\text { enter participant information directly into Axiom. For example, Safer Return sector } \\
\text { managers (employment specialists) record each participant job lead, the result of that } \\
\text { lead (employment or not), and job retention at 30, 60, and 90 days. Alternatively, if } \\
\text { participants are referred to external service agencies, reentry coaches communicate } \\
\text { directly with those service providers to determine the participants' outcomes and enter } \\
\text { those data into Axiom. }\end{array}$ \\
\hline $\begin{array}{l}\text { If a participant violates the terms of his/her parole or is arrested for a new charge, the } \\
\text { reentry coach may advocate on the participant's behalf, working with the parole officer, } \\
\text { the police department, the public defender's office, and judges to try to mitigate the } \\
\text { sanction or sentence. }\end{array}$ \\
\hline
\end{tabular}

\section{Resource Building and Maintenance Activities}

In addition to activities that serve the participant and the family directly, program staff spend a considerable amount of time building and maintaining program resources. Safer Return relies on partners to provide many critical services to its participants, including mental health and substance abuse treatment, educational and job training programming, and pro-social engagement opportunities. To facilitate these services for Safer Return participants, reentry coaches, along with Safer Return executive staff and TASC administrative staff, reach out to potential partners to solicit monetary, material, and in-kind donations (e.g., reduced waiting times for participant referrals, dedicated program slots, reduced registration fees, used clothing and furniture).

Potential partners are identified through a variety of mechanisms. The Safer Return program works with existing community boards to bolster community support for the project. These boards are also used to identify sources of programmatic support within the Garfield Park community. The program staff also has leveraged their existing relationships as community organizers, service providers, and case managers to recruit partners for Safer Return. Finally, the Safer Return program includes a contract with a local church to assist with a variety of community activities and support. The church uses its connections within and outside of the local faith community to recruit partners for the Safer Return program.

Reentry coaches work with partners to coordinate participant services. The specifics of these interactions differ substantially depending on the nature of the partnership. Examples of some of the activities the reentry coaches perform in this capacity include submitting participant service referrals, updating program materials with any scheduling or other substantive changes in program offerings, and picking up donated goods.

\section{Parole Co-case Management Activities}

A key component of the Safer Return family-inclusive case management model is its partnership with IDOC. IDOC has assigned between four and six dedicated, neighborhood-based parole officers who work primarily with Safer Return participants. The majority of Safer Return participants are on parole, and 
reentry coaches work closely with parole officers to coordinate their services through what they call cocase management. Each participant is told about the co-case management between IDOC and Safer Return during the WHPs. The purpose of this collaboration is not simply to increase the supervision of a participant, but to help synchronize services to best serve the participants' needs and ensure that participants can meet their parole requirements. Several mechanisms have been put in place to facilitate the co-case management see Table 6).

Table 6: Parole Co-case Management Activities

\begin{tabular}{l|l}
\hline $\begin{array}{l}\text { Co-case } \\
\text { Management }\end{array}$ & $\begin{array}{l}\text { The reentry coaches and parole officers hold joint case management meetings with Safer } \\
\text { Return participants at the Safer Return community site or at the participants' homes, } \\
\text { whenever possible. These co-case management meetings are periodic check-ins to } \\
\text { address client progress, as well as any specific issues that may arise. }\end{array}$ \\
\hline Information Sharing & $\begin{array}{l}\text { Safer Return and IDOC share information both formally and informally. All paroled Safer } \\
\text { Return participants are flagged in AMS (IDOC's parole database), so that reentry coaches } \\
\text { can access correctional records, including criminal history, contact information, and parole } \\
\text { requirements. In addition, when a question or issue arises concerning a particular } \\
\text { participant, the reentry coaches and parole officers will typically call or e-mail one another } \\
\text { to get more information. }\end{array}$ \\
\hline $\begin{array}{l}\text { Sponsored } \\
\text { Movement to } \\
\text { Participate in } \\
\text { Program Activities }\end{array}$ & $\begin{array}{l}\text { Individuals on parole in Illinois have certain restrictions on where and when they may } \\
\text { travel. If program activities, such as service referrals, job interviews, and educational } \\
\text { programs, cannot be completed owing to parole restrictions, reentry coaches work with } \\
\text { the parole officers to modify the restrictions. }\end{array}$ \\
\hline
\end{tabular}

\subsubsection{Outputs}

Through direct service provision and referrals to subcontracted program partners and community services, Safer Return provides each participant with the services and resources necessary to address his or her individual reentry needs. Thus, individuals participating in the family-inclusive case management, as well as their family and social support members, receive a wide variety of services. Participation in each of the Safer Return services is voluntary. The only required element of the program is participation in the case management.

\section{Internal Outputs}

Safer Return provides a variety of services exclusively for its participants, either through the reentry coaches (see Table 7) or other program staff (see Table 8). All of the following "in-house outputs" fall under the Safer Return funding pool and executive staff oversight.

\section{Table 7: Summary of Reentry Coach Outputs}

\begin{tabular}{l|l}
\hline $\begin{array}{l}\text { Transportation } \\
\text { Services }\end{array}$ & $\begin{array}{l}\text { Safer Return provides a limited number of round trip Chicago Transit Authority fare cards } \\
\text { to participants to enable them to attend program-related activities such as substance } \\
\text { abuse treatment, job readiness training, or educational programs. Where possible, the } \\
\text { reentry coaches supplement the limited number of transit cards by providing } \\
\text { transportation in their own private vehicles to assist participants in keeping appointments. }\end{array}$ \\
\hline Material Goods & $\begin{array}{l}\text { Program partners, such as churches, community support organizations, and local } \\
\text { businesses, provide Safer Return with a variety of donations. In turn, these donations are } \\
\text { passed on to participants through the reentry coaches. These donations are not regularly } \\
\text { scheduled. As various items are received, reentry coaches and program administrators } \\
\text { determine the best use. For example, the reentry coaches maintain a supply of business }\end{array}$ \\
\hline
\end{tabular}




\begin{tabular}{|c|c|}
\hline & $\begin{array}{l}\text { suits in their office that are given to participants when they need suitable attire for a job } \\
\text { interview. Reentry coaches have also distributed donated food and baby supplies on } \\
\text { multiple occasions. Both individual participants and their families are eligible to receive } \\
\text { these donated goods. }\end{array}$ \\
\hline $\begin{array}{l}\text { Life Coaching/ } \\
\text { Counseling }\end{array}$ & $\begin{array}{l}\text { While only some of the reentry coaches are certified counselors, all reentry coaches } \\
\text { provide one-on-one guidance, which they call life coaching or counseling. This life } \\
\text { coaching/counseling is not intended as a substitute for more specialized professional } \\
\text { service referrals (e.g., substance abuse treatment, job readiness training). It instead helps } \\
\text { the participant to problem solve and maintain the behaviors that are important to a } \\
\text { successful reentry (e.g., engaging in pro-social activities, attending treatment, adhering to } \\
\text { parole requirements). }\end{array}$ \\
\hline Crisis Intervention & $\begin{array}{l}\text { Reentry coaches frequently intervene in crises within participants' and families' lives. } \\
\text { Examples of common participant and family crises include altercations between family } \\
\text { members, the loss of a job, evictions, and arrests. When called to assist with a crisis, the } \\
\text { responsibility of the reentry coach is twofold. Reentry coaches help participants and } \\
\text { families deal with the immediate situation, providing potential solutions or alternatives; } \\
\text { mediating conflicts; and advocating to other involved parties such as landlords, parole } \\
\text { officers, and employers. Additionally, the reentry coaches incorporate any crises into their } \\
\text { long-term reentry planning by helping the participant anticipate, mediate, and overcome } \\
\text { any long-term repercussions of the situation. }\end{array}$ \\
\hline $\begin{array}{l}\text { Job Application and } \\
\text { Resume Assistance }\end{array}$ & $\begin{array}{l}\text { Reentry coaches walk participants through the basic steps of job applications, teaching } \\
\text { them how to make a resume, how to locate and approach potential employers } \\
\text { (electronically and in person), how to address their criminal record in an application, and } \\
\text { how to interview effectively. The program also set up a computer in the community field } \\
\text { office for participant use, allowing participants to update and print resumes, search for } \\
\text { jobs, and contact employers. }\end{array}$ \\
\hline $\begin{array}{l}\text { Substance Abuse } \\
\text { Assessments }\end{array}$ & $\begin{array}{l}\text { Some of the reentry coaches are certified to complete substance abuse assessments. Only } \\
\text { participants with histories of substance abuse or a parole mandate are assessed. A } \\
\text { participant who is found to require substance abuse treatment is referred to an } \\
\text { appropriate community partner, as the Safer Return program does not offer substance } \\
\text { abuse treatment in-house. }\end{array}$ \\
\hline
\end{tabular}

Table 8: Summary of Other Safer Return Program Outputs

\begin{tabular}{l|l}
\hline Job Readiness & $\begin{array}{l}\text { This training entails a one-week program that teaches participants basic job skills, such as } \\
\text { the application process, interviewing, punctuality, and interacting with supervisors. The } \\
\text { class itself is treated as a preliminary test of participants' job readiness. Participants must } \\
\text { demonstrate that they can show up on time every day and actively engage for the whole } \\
\text { time. Completion of the Safer-funded Job Readiness class is a prerequisite to being placed } \\
\text { in the program's job candidate pool and working with the sector managers. }\end{array}$ \\
\hline Sector Managers & $\begin{array}{l}\text { Sector managers are the Safer Return job placement specialists. The sector managers } \\
\text { work with local employers to identify potential jobs for Safer Return participants. They } \\
\text { also meet with participants to identify appropriate jobs and coach them through the } \\
\text { application and interview process. Sector managers only meet with participants who have } \\
\text { been deemed "job ready" either by completing the Job Readiness Training or CCW. }\end{array}$ \\
\hline $\begin{array}{l}\text { Civic Community } \\
\text { Works (CCW) }\end{array}$ & $\begin{array}{l}\text { CCW is a transitional job component that includes graduated 10- to 12-week job training } \\
\text { programs in handling tools/equipment and performing outdoor manual labor, including } \\
\text { minor repair work, painting, and landscaping. Participants are enrolled for 30 hours per }\end{array}$ \\
\hline
\end{tabular}




\begin{tabular}{|c|c|}
\hline & $\begin{array}{l}\text { week and are given a } \$ 125 \text { weekly stipend. Upon successful completion of the first } \\
\text { program in basic tools, participants can be graduated to the power tools CCW program, } \\
\text { where they receive training from the City of Chicago Department of Streets and Sanitation } \\
\text { in power tool operation. }\end{array}$ \\
\hline $\begin{array}{l}\text { Government- } \\
\text { Contracted Work } \\
\text { Crews }\end{array}$ & $\begin{array}{l}\text { The Safer Foundation has won multiple contracts to perform outdoor labor across } \\
\text { Chicago. Participants who have completed both CCW programs are eligible to apply for } \\
\text { these full time, paid positions. About half of these positions are temporary (9-12 months) } \\
\text { and the remainder offer permanent employment. }\end{array}$ \\
\hline Group Housing & $\begin{array}{l}\text { Safer Return originally intended to establish a self-administered recovery group home in } \\
\text { Garfield Park, based on the Oxford House }{ }^{\circledR} \text { model }^{11} \text { that has been implemented across the } \\
\text { United States, Canada, and Australia. Safer Return expected that participants would be } \\
\text { able to live in such housing if it met their needs (e.g., substance abuse recovery). } \\
\text { However, that component has not been implemented. Instead, the program makes } \\
\text { external housing referrals for participants in need of temporary residence (see External } \\
\text { Outputs, below). }\end{array}$ \\
\hline Mentoring & $\begin{array}{l}\text { NAEFIO oversees the mentoring component of Safer Return. Formerly incarcerated } \\
\text { individuals who have successfully reintegrated into the community serve as peer mentors } \\
\text { for Safer Return participants. In addition to informal, one-on-one mentoring between a } \\
\text { mentor and Safer Return mentees, NAEFIO runs twice-monthly group meetings, called the } \\
\text { reentry circle. At these meetings, individuals gather to discuss the hardships they have } \\
\text { faced during reentry, as well as their successes. The reentry circle also serves as an } \\
\text { opportunity for new participants to introduce themselves to the group and to select their } \\
\text { mentor. }\end{array}$ \\
\hline
\end{tabular}

\section{External Outputs}

If participants have reentry needs or goals that cannot be met by Safer Return services, the reentry coaches refer them to alternative service providers (see Table 9). These alternative providers are typically, though not always, program partners. Through the resource-building and maintenance activities described above, Safer Return has negotiated preferential treatment for its participants, making such services more attractive to both participants and reentry coaches.

Table 9: Safer Return External Partner Services

\begin{tabular}{l|l}
\hline $\begin{array}{l}\text { Mental Health and } \\
\text { Substance Abuse } \\
\text { Treatment }\end{array}$ & $\begin{array}{l}\text { Safer Return is not licensed to provide mental health or substance abuse treatment. If a } \\
\text { reentry coach believes that an individual needs either of these treatments or if the } \\
\text { participant has a parole board order to undergo treatment, an external referral is } \\
\text { provided. Reentry coaches primarily refer participants to outpatient treatment. Should a } \\
\text { participant enter inpatient substance abuse treatment while enrolled in the Safer Return } \\
\text { program, the participant stays enrolled in Safer Return and the reentry coach visits the } \\
\text { participant as necessary. }\end{array}$ \\
\hline Educational and Job & $\begin{array}{l}\text { GED, associate, and postsecondary coursework are all available. Additionally, Safer Return } \\
\text { has enrolled individuals in job training programs outside of the CCW program, including } \\
\text { janitorial staff training, basic computer skills training, and home refurbishing training. }\end{array}$ \\
\hline Anger Management & $\begin{array}{l}\text { If a participant wishes to attend a formal anger management program or is mandated by } \\
\text { parole to do so, reentry coaches provide an external referral. }\end{array}$ \\
\hline Transitional Housing & There are a few organizations within the Garfield Park community that provide temporary \\
\hline
\end{tabular}

${ }^{11}$ For more information on the Oxford House Model, visit http://www.oxfordhouse.org 
housing to the formerly incarcerated population. Some providers require that their tenants attend additional programming, such as vocational training, while others simply provide a place to live. Reentry coaches are aware of the requirements of each housing program and help participants choose the one most appropriate to their needs.

While Safer Return services are provided to participants free of charge, some external providers require the participants to pay for services. Safer Return maintains limited funds to help participants defer these costs. Two funding sources are available, summarized in Table 10. Reentry coaches must receive prior approval from the Safer Return executive staff for each fund distribution.

Table 10: Safer Return Participant Funding Sources

\begin{tabular}{l|l}
\hline Emergency Funds & $\begin{array}{l}\text { These funds are intended to cover one-time, unanticipated costs. For example, } \\
\text { participants who are enrolled in the CCW training program or a similar job training } \\
\text { program are required to purchase appropriate attire, such as steel-toed boots and safety } \\
\text { glasses. }\end{array}$ \\
\hline Educational Funds & $\begin{array}{l}\text { Educational funds are specifically allocated to cover of tuition, books, and fees associated } \\
\text { with educational programs. }\end{array}$ \\
\hline
\end{tabular}

Finally, reentry coaches incorporate pro-social engagement into each participant's reentry plan. Safer Return has several community partners specifically recruited to provide pro-social opportunities to participants with limited connections. These partners include both faith-based and secular organizations in the Garfield Park community. Reentry coaches offer participants information about all of the organizations and their activities for the participants to use at their discretion.

\subsubsection{Outcomes}

The primary goal of the family-inclusive case management model is successful reintegration back into the community, not simply reentry from prison. It focuses on the overall well-being of each individual, attempting to make them active and productive members of their community and families, to increase their social capital, and to decrease recidivism.

\section{Short-Term Outcomes}

Safer Return participants are eligible to receive case management services for up to one year. During this time, the program attempts to help them meet their reentry goals and begin their reintegration by pairing them with appropriate services. The short-term (one-year) outcomes of the case management reflect the receipt of those services and engagement in the family-inclusive case management process. As deemed appropriate by the reentry coaches during reentry planning, short-term outcomes for each participant may include the following:

- Participate in Safer Return activities (CCW, mentoring, Oxford House)

- Complete job readiness training

- Meet with the sector manager

- Find employment

- Enroll in an education/job training program

- Secure transitional housing

- Secure permanent housing

- Secure mental health treatment

- Secure medical treatment 
- Secure substance abuse treatment

- Complete anger management classes

- Attend pro-social community activities

Participants' family and other social support members also may be involved in the case management and be the beneficiaries of limited services. Some participants have strong family connections throughout their incarceration, making family inclusion straightforward. However, for participants who do not have strong family and social support networks upon release from prison, reestablishing connections and trust among family and social support members is an important short-term outcome.

\section{Long-Term Outcomes}

If the case management is successful, its impact extends beyond the one-year service period. Through participation in Safer Return, individuals are paired with the services necessary to complete their reentry goals, which are in in turn designed to lead to the longer-term outcomes associated with successful reintegration. Specific long-term outcomes include the following:

- Permanent employment

- Reduced recidivism

- Improved family relationships

- Increased physical and mental health

- Increased community engagement and pro-social activity

Successful reintegration ultimately improves the well-being of individuals, their families, and their community. Individuals become active and productive community members, working to improve their community and support their family.

\subsection{Family Members' Characteristics and Experiences}

Below, the baseline characteristics of the first 100 family members recruited into the study are described. As previously mentioned, family members complete a baseline survey four months following the release of their formerly incarcerated family member. The baseline survey covers three time frames: 1) four months prior to their family member's most recent incarceration (pre-incarceration), 2) during their most recent incarceration (during incarceration), and 3) four months following their most recent release (post-release). The baseline survey covers several domains: demographics; relationship, contact, and activities with the returning family member; support the formerly incarcerated person provides for any children or dependents the family member provides care for; resources the family member has provided to the returning prisoner and the level of difficulty involved for the family member; the family member's experiences with social service agencies; challenges involved with the returning prisoner; and services or resources the family member needs. This report discusses data on the family members' characteristics, relationships, contact, and attachment to the returning individual and access to services.

As shown in Table 1, sample recruitment for formerly incarcerated persons and their family members proceeded more quickly in the comparison community, West Englewood (WE), than in Garfield Park (GP). Of the 100 family members described herein, 37 were family members of a Safer Return participant and the remaining 63 were family members of formerly incarcerated individuals returning to the comparison community. Table $\mathbf{1 1}$ describes some key baseline characteristics of the family members in each community. 
Table 11. Characteristics of the Family Members of Formerly Incarcerated Persons in Garfield Park (GP) and West Englewood (WE), at Four Months Post-Release

\begin{tabular}{|c|c|c|}
\hline & GP & WE \\
\hline \multicolumn{3}{|l|}{ Employment and Income } \\
\hline Employed at least part time & $32.4 \%$ & $38.7 \%$ \\
\hline Number of jobs (average) & 1.1 & 1.1 \\
\hline Number of hours worked per week at all jobs (mode) & $31-40$ & $31-40$ \\
\hline Annual income from all sources (mode) & $<\$ 10,000$ & $<\$ 10,000$ \\
\hline \multicolumn{3}{|l|}{ Education (percentage) } \\
\hline Less than high school & 32.4 & 38.1 \\
\hline High school graduation/GED & 40.5 & 33.3 \\
\hline Some college & 13.5 & 19.0 \\
\hline Associate's degree & 2.7 & 1.6 \\
\hline Bachelor's degree or above & 10.8 & 7.9 \\
\hline \multicolumn{3}{|l|}{ Marital Status (percentage) } \\
\hline Never married & 45.9 & 49.2 \\
\hline Married & 35.1 & 22.2 \\
\hline Separated / Widowed / Divorced & 18.9 & 28.6 \\
\hline \multicolumn{3}{|l|}{ Criminal History (percentage) } \\
\hline Ever arrested & 32.4 & 28.6 \\
\hline Ever served a prison or jail sentence & 13.5 & 4.8 \\
\hline \multicolumn{3}{|l|}{ Perceptions of Quality of Life* } \\
\hline Housing & 3.4 & 3.8 \\
\hline Job & 2.7 & 2.8 \\
\hline Health & 3.2 & 3.8 \\
\hline Overall financial situation & 2.5 & 2.7 \\
\hline Involvement in community & 2.3 & 2.4 \\
\hline Support system & 2.4 & 2.5 \\
\hline \multicolumn{3}{|l|}{ Gender (percentage) } \\
\hline Male & 25.0 & 12.7 \\
\hline Female & 75.0 & 87.3 \\
\hline
\end{tabular}

* Where 1 is poor and 5 is excellent

In general, the family members who completed the survey have limited resources (Table 11). Roughly one-third of all family members were employed at the time of the survey, and nearly half (47.1 percent in GP and 49.2 percent in WE) were living on less than $\$ 10,000$ per year. More than 70 percent of family members in each community earned a high school diploma/GED or never completed high school, and nearly one-third had been arrested in the past. Moreover, the family members surveyed had a generally low outlook on their situation, rating their quality of life at or below average across multiple measures. Indeed, only family members' ratings of their health and housing, in both communities, were on the higher end of the scale (three out of five).

As mentioned, the family-inclusive case management model defines family loosely, to include not only biological family members, but also close friends, faith leaders, mentors, and other sources of social support. Despite this, the family members included in the survey, as identified by the formerly incarcerated persons, tended to fall into a traditional family member category. In each community, more than 60 percent were a parent, girlfriend or boyfriend, or sibling of the formerly incarcerated 
individual. Only 5 percent of the survey respondents were a friend or preacher or spiritual adviser. Respondents also were overwhelmingly female-more than 75 percent in each community. This is notable given that the study recruits formerly incarcerated males only (Table 12).

Table 12. Relationship between Family Members and Formerly Incarcerated Persons in Garfield Park (GP) and West Englewood (WE), at Four Months Post-Release

\begin{tabular}{|c|c|c|}
\hline & GP & WE \\
\hline \multicolumn{3}{|l|}{ Living Arrangements (percentage) } \\
\hline Lived with before prison & 71.9 & 63.3 \\
\hline Lives with currently & 75.1 & 76.7 \\
\hline \multicolumn{3}{|l|}{ How are you connected to FIP... (percentage) } \\
\hline Parent or step-parent & 32.4 & 19.0 \\
\hline Girlfriend, boyfriend, partner, or fiancée & 21.6 & 23.8 \\
\hline Sister, brother, stepsister, or stepbrother & 10.8 & 22.2 \\
\hline Grandparent & 5.4 & 12.7 \\
\hline Wife or husband & 2.7 & 7.9 \\
\hline Friend before prison & 10.8 & 0.0 \\
\hline Cousin & 8.1 & 3.2 \\
\hline Aunt or uncle & 2.7 & 4.8 \\
\hline Child, stepchild, or foster child & 2.7 & 3.2 \\
\hline Preacher or Spiritual Advisor & 2.7 & 0.0 \\
\hline Other & 0.0 & 3.2 \\
\hline Ex-girlfriend, ex-boyfriend, ex-partner, or ex-fiancée & 0.0 & 0.0 \\
\hline Former wife or husband & 0.0 & 0.0 \\
\hline Friend after prison & 0.0 & 0.0 \\
\hline
\end{tabular}

A majority of the family members who responded to the survey are currently living with the formerly incarcerated individuals in each community. In addition to living together, family members report high levels of contact with the formerly incarcerated person. Table 13 shows the levels of communication before, during, and after prison via face-to-face and electronic media. In general, the communication patterns in each community were similar; respondents in both communities reported routine communication after their family members' release from prison, both face-to-face contact and through electronic media. Communication post-release is greater than the levels of communication before prison, though the pre-release contact appears to be routine for a majority of the family respondents as well. During prison, as can be expected, communication between the family members dropped substantially. It is also noteworthy that across all measures of contact, pre-, during, and post-release, respondents in West Englewood reported higher levels than respondents in Garfield Park. In particular, more than half ( 51 percent) of family members in West Englewood reported weekly contact while their family member was in prison, compared to only 32 percent of Garfield Park family members.

Table 13. Forms of Contact between Family Members and Formerly Incarcerated Persons in Garfield Park (GP) and West Englewood (WE), at Four Months Post-Release

\begin{tabular}{l|c|c}
\hline & GP & WE \\
\hline Levels of Contact (percentage) & & \\
\hline At least weekly contact before prison & & \\
\hline Face-to-face & 86.5 & 88.9 \\
\hline Phone/text/email & 70.3 & 74.6 \\
\hline
\end{tabular}




\begin{tabular}{l|c|c}
\hline & GP & WE \\
\hline Levels of Contact (percentage) & & \\
\hline At least weekly contact during prison & & \\
\hline Any type of contact & 32.4 & 50.8 \\
\hline At least weekly contact after prison & & \\
\hline Face-to-face & 97.3 & 100.0 \\
\hline Phone/text/email & 70.3 & 79.4 \\
\hline
\end{tabular}

Across both communities, the high levels of communication are mirrored by the reportedly strong attachment that family members have with their formerly incarcerated family member. Respondents were asked to indicate whether they agreed with a series of statements describing the nature of their relationship with their formerly incarcerated family member. The results, summarized in Table14, indicate that family members hold strong, positive, and meaningful relationships with their formerly incarcerated family member.

Table 14. Forms of Attachment between Family Members and Formerly Incarcerated Persons in Garfield Park (GP) and West Englewood (WE), at Four Months Post-Release

\begin{tabular}{l|c|c}
\hline & GP & WE \\
\hline Post-Release Level of Attachment* (percentage) & & \\
\hline Felt close to (formerly incarcerated) family member & 100.0 & 100.0 \\
\hline Wanted family member to be involved in his/her life & 97.3 & 100.0 \\
\hline Family member has been a source of emotional support & 86.5 & 88.9 \\
\hline Satisfied with communication with family member & 100.0 & 92.1 \\
\hline Can calmly discuss problems with family member & 97.3 & 93.7 \\
\hline Can express true feelings to family member & 91.9 & 98.4 \\
\hline
\end{tabular}

*Percentage who either strongly agreed or somewhat agreed with the statements; note that family member in this context is the formerly incarcerated person.

Despite their limited resources, as demonstrated in Table 11, the family members who responded to the survey appear to provide myriad resources to returning individuals upon their release. Family members were asked what services they either provided directly or helped their formerly incarcerated family member find (Table 15). Financial support, food assistance, and employment were the most common services provided by family members, with about half of respondents in each community reporting that they provide each of those services. When comparing the two communities, it appears that service provision was remarkably very similar, except for two services: drug and alcohol treatment and child care. Among respondents in West Englewood, approximately 10 percent reported helping their family member secure drug and alcohol treatment and 11 percent reported helping with child care. In comparison, fewer than 3 percent of family members in Garfield Park reported providing these services.

Table 15. Resources Provided by Family Members for Formerly Incarcerated Persons in Garfield Park (GP) and West Englewood (WE), at Four Months Post-Release

\begin{tabular}{|c|c|c|}
\hline & GP & WE \\
\hline \multicolumn{3}{|c|}{ Helped your family member find or access to ... (percentage) } \\
\hline Food/food assistance programs & 59.5 & 54.0 \\
\hline Employment & 48.6 & 47.6 \\
\hline Transportation & 45.9 & 47.6 \\
\hline Financial support & 45.9 & 44.4 \\
\hline Community activities (e.g., church, recreational) & 29.7 & 23.8 \\
\hline
\end{tabular}




\begin{tabular}{|c|c|c|}
\hline & GP & WE \\
\hline \multicolumn{3}{|c|}{ Helped your family member find or access to ... (percentage) } \\
\hline Housing & 24.3 & 27.0 \\
\hline Enroll in an educational program & 21.6 & 28.6 \\
\hline Enroll in a job training program & 24.3 & 25.4 \\
\hline Medications and health care & 18.9 & 22.2 \\
\hline Child care & 2.7 & 11.1 \\
\hline Drug and/or alcohol treatment & 2.7 & 9.5 \\
\hline Mental health counseling & 5.4 & 6.3 \\
\hline Parenting/relationship classes & 2.7 & 6.3 \\
\hline
\end{tabular}

\subsection{Reflections from Family Members and Formerly Incarcerated Persons}

To weave qualitative themes through the survey instruments, UI conducted focus groups in January, June, and November 2010 with family members and formerly incarcerated persons in each community. These discussions were approximately an hour each in length and covered the process of returning home to the community, experiences with the Safer Return program or business as usual, and relationships between formerly incarcerated individuals and their family members.

Based on the focus groups, it was clear that formerly incarcerated individuals and their family members across both communities had the following perceptions regarding prisoner reentry and the role that family members play in it:

- Individuals are not adequately prepared to return home.

- Individuals rely heavily upon their family members for support after release.

- Family support is strongest immediately following release from prison and can atrophy over time.

Safer Return participants and their family members also reported both positive and negative experiences with the Safer Return case management.

In the focus groups with formerly incarcerated persons, respondents generally reported that they felt unprepared for their transition back home. They believed that the limited programming provided by IDOC was not adequate to prepare them and, in some cases, it was viewed as detrimental, because it provided outdated and incorrect resource information. Furthermore, upon return to the community, there was general consensus that the parole officers were too busy to provide any meaningful assistance once they were released. Individuals reported receiving only $\$ 10$ in gate money from the state upon release, making it difficult to support themselves. As such, the large majority of individuals said that they primarily rely on their family and social support networks to help support them when they return.

It appears that this support is given regardless of the relationship between individuals and family members during incarceration. For a variety of reasons, many individuals did not stay in close contact with their family members during prison. This aligns with our survey findings that showed a reduction in communication during prison. In the focus groups, formerly incarcerated persons stated that some family members refused to contact them, giving them what they called "tough love," while others simply could not afford the transportation and telephone costs associated with staying in contact during their incarceration.

Nevertheless, the family members were happy to have the released individual back home and to provide support. Individuals and family members both attribute this to the excitement of release and 
reunification. Family members reported feeling hopeful about the formerly incarcerated individual's return and were optimistic that positive behavioral changes were possible. Over time, however, the relationships between individuals and their family and social support members can become strained. Individuals who cannot regain independence can overstay their welcome and become a burden to their family and other social support members. As seen in the baseline survey results, family members of formerly incarcerated individuals have limited resources, yet provide the formerly incarcerated individuals with a variety of resources. While family members did not appear to be angry or resentful over helping in these various ways, they did acknowledge that they often struggle financially in providing this assistance.

Safer Return participants had mixed opinions about whether the Safer Return case management was helpful in addressing their needs. For example, some reported encountering challenges finding resources, while others were satisfied with the services they received. Each participant's opinion of the program seemed to be dependent on their opinion of the individual reentry coach with whom they were matched. Some formerly incarcerated individuals did not feel that their reentry coach cared about them or their reintegration, and consequently they did not participate in program activities.

Family and social support members shared similarly mixed opinions about the Safer Return program. While a few reported various benefits they received through the program (such as bus passes or referrals), many had experienced limited contact with reentry coaches. Notably, none of the interviewed family members considered themselves to be direct beneficiaries of Safer Return services. Instead, family members were focused on the success of the formerly incarcerated individuals. Even those family and social support members who had regular contact with the reentry coaches reported that they did not go to address their own needs; they went to help enhance services for their formerly incarcerated family member. In their opinion, the program could best serve them by putting all its efforts toward helping their formerly incarcerated family members. Family members did, however, express a desire for support. In the focus groups, family members from both communities suggested that support groups, where they could meet with others in similar situations (a family member is incarcerated or has recently returned), would be helpful. 


\section{Conclusions}

As demonstrated through the survey findings and the focus group discussions, the family members in the treatment and comparison group displayed similar response patterns, with a few notable differences. In general, family members considered their relationships with their formerly incarcerated family members to be strong and positive. Families appear highly supportive of their formerly incarcerated family members, wanting to provide assistance in any way possible. Family members in the treatment and comparison communities appeared to be generally low income, never married, had achieved a high school diploma/GED or lower, and were female. The majority of respondents in both communities, approximately three-quarters, were not employed at all. Though tests for statistical differences were not conducted on the survey responses, given the low base numbers, a few baseline characteristics of family members in Garfield Park demonstrated that they were perhaps more disadvantaged than their West Englewood counterparts. A higher percentage of family members in Garfield Park had been arrested before and served a prison or jail sentence than family members in West Englewood reported. Also, Garfield Park family members had lower overall perceptions of their quality of life than those in West Englewood.

Despite their limited resources, which would understandably affect the provision of resources, family members in the survey reportedly provide a great deal of resources to family members. The biggest resource appears to be housing. The majority of family members in the treatment and comparison communities were currently living with their formerly incarcerated family member. Though it cannot be determined from the survey questionnaire, it is reasonable to assume that the family members are providing the housing resource to the formerly incarcerated person, instead of the other way around, given the timing from release to the baseline survey. Many of the family members reported living with the formerly incarcerated person before their most recent prison stay, as well. This might indicate that formerly incarcerated persons are likely to view those they are or have lived with as their most significant source of social support, regardless of who that person is. The survey shows that this individual is most likely a biological family member (e.g., parent, grandparent, or sibling) or a significant other (e.g., girlfriend, boyfriend, or partner). Interestingly, only about one-quarter of the family members in each community said that they helped their formerly incarcerated family member find or access housing. It could be that respondents who live with their formerly incarcerated family member do not see their provision of housing as assistance, or that they interpreted the question to mean assistance with finding housing other than their current situation.

\subsection{Implications}

Given that the family members surveyed appear to be involved in the lives of formerly incarcerated persons in significant ways, these family members should be viewed as a resource. At minimum, the formerly incarcerated persons are likely to live with family members; therefore, programs such as Safer Return that try to engage family members in the reentry process should do well. Unfortunately, many family members engaged in the focus group discussions, including family members of Safer Return participants, stated that they did not feel part of the reentry process, through service providers, case managers/reentry coaches, or parole officers. Many indicated that they never had contact with any of their formerly incarcerated family members' case managers/reentry coaches or parole officers. This was confirmed through preliminary analyses of the survey instrument, as well (not shown). Supporting families during the reentry process in a broad way, particularly those with whom formerly incarcerated persons are residing, should be part of the reentry process. As shown in other studies and confirmed in the present analysis, these family members are likely to be low income with limited resources.

Therefore, support in the form of programs that offset the financial burdens of family members appears to be critical. This financial support could come in the form of clothing, food, and transportation- 
resources that formerly incarcerated persons might logically rely on their family members to provideas well as employment training, transitional and permanent employment opportunities, and housing placements that benefit family members directly. Emotional support could be critical, too. Though the overwhelming majority of family respondents surveyed in each community said their formerly incarcerated family member was a source of emotional support, programs that provide emotional support to family members in dealing with the formerly incarcerated persons also may be beneficial. Indeed, family members in at least one of the focus groups suggested that a support group for family members of incarcerated persons would benefit them greatly. The survey could be reflecting that just having a family member back home from incarceration is emotionally supportive.

\subsection{Next Steps}

The evaluation relies on multiple methods to assess the process and impact of the family-inclusive case management model on outcomes of individuals recently released from prison and their family members. The information in this report was based on data collected through semi-structured stakeholder interviews, surveys, and focus groups, as well as program and administrative records from Safer Return staff and their partners. The evaluation team continues to administer the baseline and follow-up survey instrument to family members of formerly incarcerated persons in each neighborhood.

Follow-up surveys are administered to family members approximately six months after the baseline surveys are completed or approximately ten months after formerly incarcerated family members are released from prison. The follow-up family survey includes domains and constructs similar to the baseline survey, asking family members to reflect on changes to their relationship, contact, and activities with the returned prisoner since the baseline survey. In addition, the survey asks about changes in the family member's own need for assistance, experiences with social service agencies, and any challenges associated with their family member who was recently released from prison. The survey also asks appropriate respondents about the children of formerly incarcerated persons and their relationship and contact. Due to difficulties contacting the family members at follow-up, the evaluation team has used a mixed-method approach to collect the follow-up data.

In addition to the difficulties with program start-up and initial sample recruitment, the evaluation team is experiencing challenges with sample attrition or low participation in the follow-up surveys. There are several reasons for the sample attrition. Of those who have not completed a follow-up survey within the six-month window, approximately one-third were unreachable due to disconnected lines, incorrect numbers, or because they were deceased; another one-third never answered the phone after multiple attempts by the research team. Only three people have flatly refused to take the follow-up survey. To target the group that does not answer their phones, the evaluation team has implemented several strategies, including mailing information about the study before potential participants receive phone calls, mailing paper surveys with return postage included, altering calling schedules and callers, and holding in-person survey sessions in Chicago. At the time of this report, 38 surveys were completed out of 94,20 of which are still being actively recruited. Of those 38,28 were completed by phone ( 74 percent), 9 were completed through mailed surveys ( 24 percent), and 1 was conducted in person ( 3 percent).

Over the next few months of the study, projected to end March 2012, UI researchers will continue to work with Safer Return executive staff and their partners to overcome the challenges with study enrollment to try to draw a sufficient sample of participants on which to base meaningful conclusions about the program's impact. At the end of June 2011, 161 family members were enrolled in the research study-67 in the treatment community (Garfield Park) and the remaining 94 in the comparison community (West Englewood). Assuming previous numbers, an additional 12 to 15 family members will 
be enrolled in the study monthly. Though it is difficult to know whether the final sample will be sufficiently large to detect statistical differences between the treatment and comparison groups, the evaluation team suspects that current enrollment numbers will hinder a rigorous evaluation focused on the impact of the family-inclusive case management service. Indeed, a total sample size of less than 200 family members with unequal numbers in the treatment and comparison groups, suggests that the effect of Safer Return's case management on outcomes needs to be sufficiently large to be detected in the current sample. The study's current challenges with sample attrition threaten the statistical power of the study even further.

Regardless of the final sample size achieved for the study, UI will employ both descriptive and multivariate statistical methods to explore how the treatment and comparison groups differ with respect to the study's research questions. At minimum, the study will provide critical information about the role that families and social support networks play in supporting or undermining the reentry efforts of individuals returning from incarceration. Further, since Safer Return is a collaborative effort among faith- and community-based, city, and state agencies, the study will illustrate how the family can offer a low-cost vehicle for leveraging these institutional investments to reduce recidivism and lead to better reintegration among individuals returning from prison to the community. 


\section{References}

Bradley, D. E. 1995. "Religious Involvement and Social Resources: Evidence from the Data Set 'Americans' Changing Lives.'” Journal for the Scientific Study of Religion 34: 259-67.

Clark, M. D. 2005. "Motivational Interviewing for Probation Staff: Increasing the Readiness to Change." Federal Probation 69: 22-30

DeJong, P., \& I. K. Berg. 2002. Interviewing Solutions. Pacific Grove, CA: Brooks/Cole.

diZerega, M., \& S. V. Agudelo. 2011. Piloting a Tool for Reentry: A Promising Approach to Engaging Family Members. New York: Family Justice Program, Vera Institute of Justice.

Early, T. J., \& L. F. Glen Maye. 2002. "Valuing Families: Social Work Practice with Families from a Strength Perspective." Social Work 45: 118-30.

La Vigne, N., C. Visher, \& J. Castro. 2004. Chicago Prisoners' Experiences Returning Home. Washington, DC: The Urban Institute.

Quinn, W. H., \& D. J. Van Dyke. 2004. “A Multiple Family Group Intervention for First-Time Juvenile Offenders: Comparisons with Probation and Dropouts on Recidivism." Journal of Community Psychology 32: 77-100.

Selber, K., T. Johnson, \& M. Lauderdale. 1993. "The FSP Family/Community Support Model: Natural Support Networks." Paper presented at the North American Conference on the Family and Corrections, Quebec City, Quebec, Canada, October 10-12.

Solomon, A., C. Visher, N. La Vigne, \& J. Osborne (Eds.). 2006. Understanding the Challenges of Prisoner Reentry: Research Findings from the Urban Institute's Prisoner Reentry Portfolio. Washington, DC: The Urban Institute.

Sullivan, E., M. Mino, K. Nelson, \& J. Pope. 2002. Families as a Resource in Recovery from Drug Abuse: An Evaluation of La Bodega de la Familia. New York: Vera Institute of Justice.

Travis, J., \& C. Visher. 2005. Prisoner Reentry in America. New York: Cambridge University Press.

Travis, J., A. Solomon, \& M. Waul. 2001. From Prison to Home: The Dimensions and Consequences of Prisoner Reentry. Washington, DC: The Urban Institute.

Tripodi, S. J., J. S. Kim, \& K. Bender. 2010. "Is Employment Associated with Reduced Recidivism? The Complex Relationship between Employment and Crime." International Journal of Offender Therapy and Comparative Criminology 54: 706-20.

Visher, C., \& S. Courtney. 2007. One Year Out, Experiences of Prisoners Returning to Cleveland. Washington, DC: The Urban Institute

Visher, C., V. Kachnowski, N. La Vigne, \& J. Travis. 2004. Baltimore Prisoners' Experiences Returning Home. Washington, DC: The Urban Institute. 
